Original Paper

\title{
出口構造改良型遠心分離機による微粒子の分級
}

\section{Experimental and Computational Study of Classification of Particles by Improved Centrifugal Separator}

\author{
山本 徹也, 小谷 俊枝, 福井 国博, 吉田 英人 \\ Tetsuya Yamamoto, Toshie Kotani, Kunihiro Fukui, Hideto Yoshida
}

Received 27 June 2007 ; Accepted 4 October 2007

This study investigated the particle classification performance of an improved centrifugal separator. The improvements made in the centrifugal separator were the installation of another outlet near the wall of the conventional centrifugal separator and a ring partition in the outlet tube. As a result, it was found that $95 \%$ cut size of the centrifugal separator was lowered by reducing the ratio of fine particle's flow rate to the total flow rate because large fraction of coarse particles were collected into the outlet tube near the wall. The ring partition improved the particle classification performance because it prevented the mixing between fine and coarse particles. These experimental results were qualitatively in agreement with the predictions by the computational simulation.

Keywords : Centrifugation, Particle size classification, Partition, Computational simulation

\section{1. 緒 言}

近年，粉体工学の分野では計算機シミュレーション による研究が盛んに行われている。筆者らは，これま でサイクロンを始め様々な分級装置内における流体及 び微粒子の挙動について数値シミュレーションを行 い，その結果と実験結果を比較検討してきた。その結 果，両者は少なくとも定性的に一致しており，相互の 妥当性を示すことに成功している ${ }^{1 \sim 5)}$ 。

遠心分離機に関する数值シミュレーションについて は，筆者らは前報においてその内部流体解析を行い, 実験結果との整合性について議論した ${ }^{6)}$ 。本研究で は，遠心分離機部内部における流体のみならず微粒子 の挙動についても数值シミュレーションを行い, その 分級性能について検討した。今回扱った遠心分離機部 では, 前報の装置 ${ }^{6)}$ と比へて出口構造について下記に 示す改良を加えた。

(1) 従来の中心軸側出口に加え, 外壁面側に新たな

広島大学大学院 工学研究科 物質化学システム専攻 (テ739-8527 東広島市鏡山一丁目 4-1) TEL 082-424-7853 Department of Chemical Engineering, Hiroshima University (1-4-1, Kagamiyama, Higashi-hiroshima 739-8527, Japan)
出口を設置

(2) (1)に関連して二つの出口を仕切るリング状の仕 切板の設置

以上の改良の結果，分級性能の向上を図る場合，二 つの出口流量の比とリング状仕切板径をパラメーター に設定し，その最適値について検討することが重要な 課題となる。本報では遠心分離機に関して，これらの パラメーターが分級性能に与える影響について数值シ ミュレーションを行い，得られた結果に対して実験的 検証を行い興味ある知見を得たので報告する。

\section{2．実験装置及び方法}

実験に用いた遠心分離機（関西遠心分離機製作所 （株）製）の装置全体概略図を Fig. 1 に示す。遠心分離 機部塔頂部に設置された回転機構によって，遠心分離 機部全体が回転する構造になっている。

試験粉体には密度 $2300 \mathrm{~kg} / \mathrm{m}^{3}$ の真球状微粒子であ るシリカ粒子（アドマテック（株）製， $\mathrm{SO}-\mathrm{C} 2$ ）を用 いた。この粉体を温度 $30^{\circ} \mathrm{C}$ に保たれた水で満たされ ているスラリータンク内に投入し，粒子濃度が $0.5 w t$ \%になるよう調製し，超音波分散機によって分散さ せ原料液とし，ポンプにて遠心分離機部塔底部から塔 


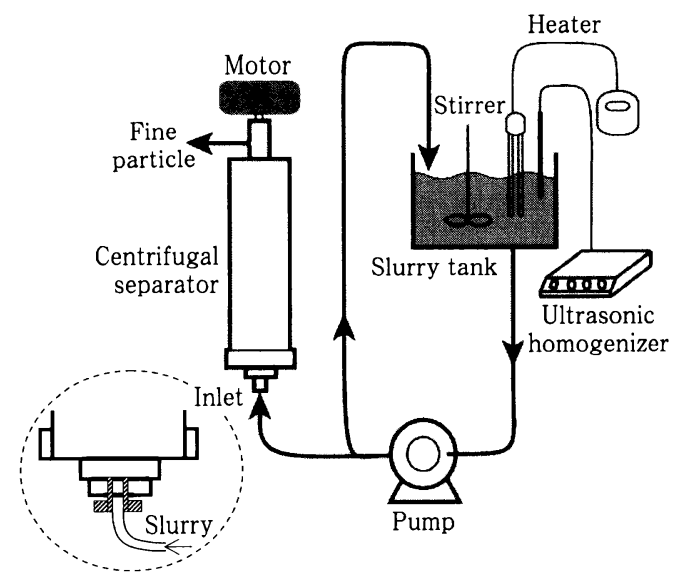

Fig. 1 Experimental apparatus

頂部に向けて供給した。このときの原料スラリー液の 粒度分布を Fig. 2 に示す。

遠心分離機部の全長及び内径はそれぞれ $302 \mathrm{~mm}$ ， 44.4mm であり, 各部の寸法を Fig. 3 (a) に示す。遠 心分離機部内部には，流体に剛体回転に近い回転を与 えるため, Fig. 3 (b) に示す 4 枚羽根を挿入した ${ }^{6)}$ 。 また, 羽根の塔頂部側に Fig. 3 (c) に示す肉厚 $1 \mathrm{~mm}$, 外径 $2 r_{\mathrm{p}}$ のリング状仕切板を装着して分級性能の向 上を図る実験についても検討した。この 4 枚羽根にリ ング状仕切板を装着した模式図を Fig. 3 （d）に示 す。

遠心分離機部塔頂部出口付近での流路の断面模式図 をFig. 4 に示す。本研究で用いた遠心分離機部は, 従 来型 ${ }^{6)}$ とは異なり遠心分離機部外壁面側に粒度の大き いスラリー液（重液）を排出する重液孔と中心軸側に それに比へて粒度の小さいスラリ一液（軽液）を排出 する軽液孔の 2 種類の孔がある構造になっている。 $Q_{\mathrm{t}}$ を遠心分離機部へ塔底部から原料を供給する流

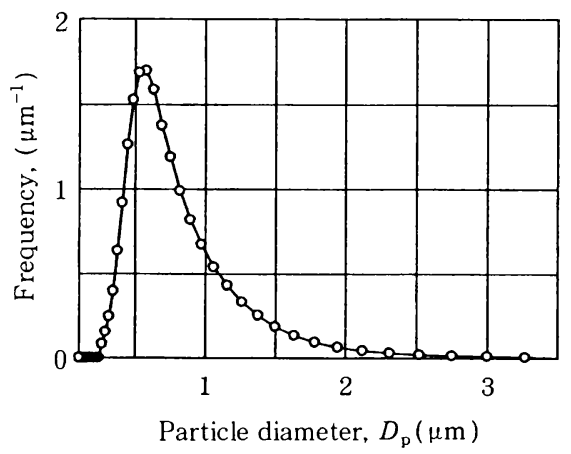

Fig. 2 Particle size distribution of the silica particles

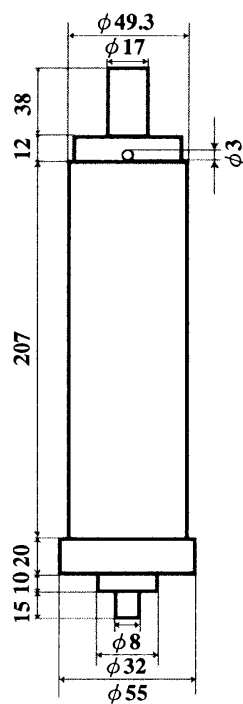

(a) Centrifugal separator

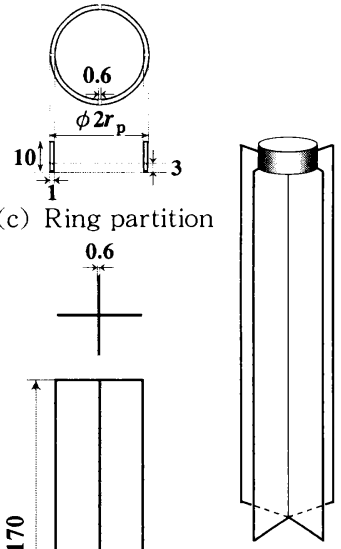

(d) Blade with ring partition

Fig. 3 Schematic diagrams of centrifugal separator, blade, ring partition and blade with ring partition

量， $Q_{\mathrm{f}}$ を塔頂部から排出される軽液流量と定義す る。軽液と原料液の流量比 $Q_{\mathrm{f}} / Q_{\mathrm{t}}$ を $\alpha$ と定義し, こ の $\alpha$ をFig. 4 に示す内径サイズ可変のスペーサーリ ングにより重液孔の大きさを変化させることで制御し た。 $\alpha=1.0$ の場合は重液孔がスペーサーリングによ

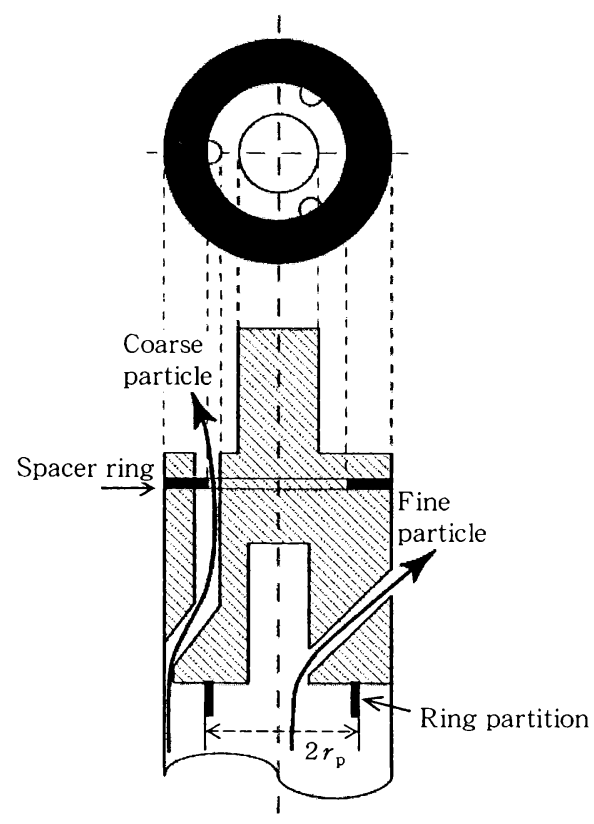

Fig. 4 Schematic representation of outlet structure of the centrifugal separator 
りふさがることになるので, この改良型遠心分離機は 従来型遠心分離機6) と同じ出口構造をとることにな る。

遠心分離機の運転条件については, 回転速度 $\omega=$ $6000 \mathrm{rpm}$, 原料供給流量 $Q_{\mathrm{t}}=600 \mathrm{ml} / \mathrm{min}$ とし, 微 粒子の分級実験を行った。遠心分離機部へスラリー供 給後, 滞留時間の $1.5 \sim 2$ 倍程度の間供給し続け, 遠 心分離機部塔頂部から排出される微粉を含む軽液を採 取した。その質量及び粒度分布を測定し，Eq. (1) で 定める部分分離効率 $\Delta \eta$ を算出した。なお，重液に含 まれる粉体及び遠心分離機部壁面に沈着した粉体は粗 粉として扱った。算出した $\Delta \eta$ を縦軸に粒子径 $D_{\mathrm{p}}$ を 横軸に取り部分分離効率曲線を描き，分級性能につい て評価した。Eq. (1) において， $m_{0}, m_{\mathrm{f}}$ は，それぞ れ単位時間あたりに遠心分離機部へ供給される原料粉 及び遠心分離機部から排出される軽液に含まれる微粉 の質量を, $f_{\mathrm{o}}\left(D_{\mathrm{p}}\right), f_{\mathrm{f}}\left(D_{\mathrm{p}}\right)$ は原料粉, 微粉の体積基準 頻度分布関数を表す。粒子径分布の測定には粒子径が $100 \mathrm{~nm}$ 以上のシリカ粒子を検知することのできるレ 一ザ回折式測定装置（日機装（株）製，MT3300EXII） を用いたが，必ずしも定量的に正しいデータが得られ るわけではないので，本報では定量的な議論は避け， 定性的な議論を導くことにした。

$$
\Delta \eta=\frac{m_{\mathrm{o}} f_{\mathrm{o}}\left(D_{\mathrm{p}}\right) \Delta D_{\mathrm{p}}-m_{\mathrm{f}} f_{\mathrm{f}}\left(D_{\mathrm{p}}\right) \Delta D_{\mathrm{p}}}{m_{\mathrm{o}} f_{\mathrm{o}}\left(D_{\mathrm{p}}\right) \Delta D_{\mathrm{p}}}
$$

\section{3. 数值シミュレーション方法}

遠心分離機において，回転速度 $\omega=6000 \mathrm{rpm}$, 原 料供給流量 $Q_{\mathrm{t}}=600 \mathrm{ml} / \mathrm{min}$ の条件下における粒子 の部分分離効率を以下の手法を用いて数値シミュレー ションにより算出した。

まず，遠心分離機部内部流体の速度場の決定につい ては, 簡略化のため, 遠心分離機部内部の流動を 2 次 元軸対称であると仮定し, Eqs. (2) 〜 (5) に示す連 続の式, 円柱座標における $\boldsymbol{z}, \boldsymbol{r}$ 方向 Navier - Stokes 式，粒子に関する拡散方程式 ${ }^{7)}$ を離散化し，コント ロールボリューム法を用いて計算した ${ }^{8)}$ 。また, 圧力 場の算出には SIMPLE (Semi-Implicit Method for Pressure-Linked Equation）法を用いた。 $z, r$ 方向 の格子分割数は， 50 及び 51 とした。Fig. 5 に境界条 件を示す。物体壁面での流体速度 $u_{z}, u_{\mathrm{r}}$ を 0 とした。

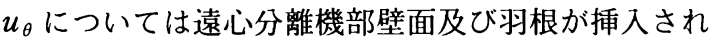
ている区間，すなわち Fig. 5 の斜線領域について は, 流体が剛体回転していることを仮定するため $r \omega$

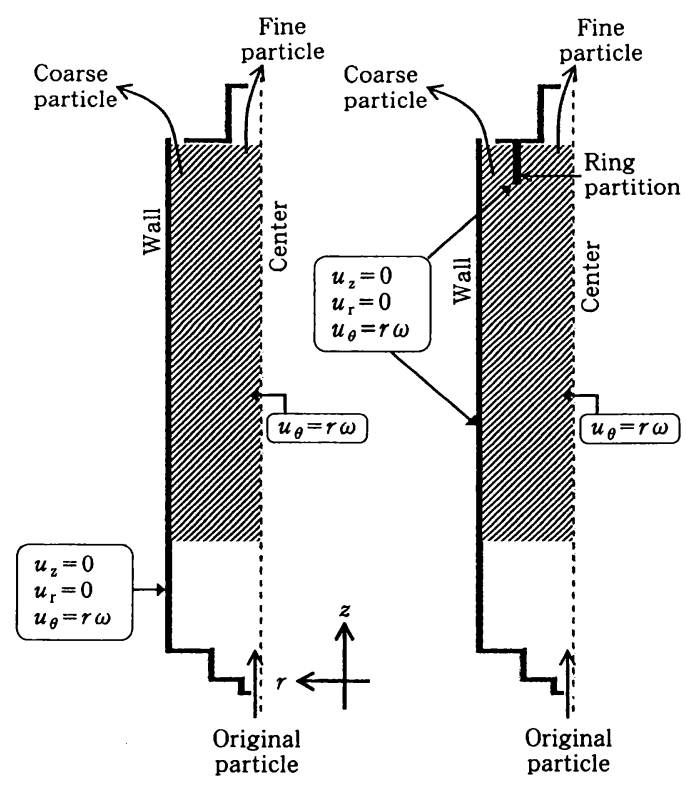

(a) Without ring partition (b) With ring partition

Fig. 5 Schematic representation of boundary conditions for numerical simulation

とした。

$$
\begin{aligned}
& \frac{\partial r u_{\mathrm{r}}}{\partial r}+\frac{\partial r u_{z}}{\partial z}=0 \\
& \rho\left(\frac{\partial u_{z}}{\partial t}+u_{\mathrm{r}} \frac{\partial u_{z}}{\partial r}+u_{\mathrm{z}} \frac{\partial u_{z}}{\partial z}\right) \\
= & -\frac{\partial p}{\partial z}+\mu\left[\frac{1}{r} \frac{\partial}{\partial r}\left(r \frac{\partial u_{\mathrm{z}}}{\partial r}\right)+\frac{\partial^{2} u_{\mathrm{z}}}{\partial z^{2}}\right]+\rho g \\
& \rho\left(\frac{\partial u_{\mathrm{r}}}{\partial t}+u_{\mathrm{r}} \frac{\partial u_{\mathrm{r}}}{\partial r}-\frac{u_{\theta}^{2}}{r}+u_{\mathrm{z}} \frac{\partial u_{\mathrm{r}}}{\partial z}\right) \\
= & -\frac{\partial p}{\partial r}+\mu\left[\frac{\partial}{\partial r}\left(\frac{1}{r} \frac{\partial r u_{\mathrm{r}}}{\partial r}\right)+\frac{\partial^{2} u_{\mathrm{r}}}{\partial z^{2}}\right] \\
& \frac{\partial r C}{\partial t}+\frac{\partial r C v_{\mathrm{r}}}{\partial r}+\frac{\partial r C v_{z}}{\partial z} \\
= & D\left[\frac{\partial}{\partial r}\left(r \frac{\partial C}{\partial r}\right)+\frac{\partial}{\partial z}\left(r \frac{\partial C}{\partial z}\right)\right]
\end{aligned}
$$

次に, 上記の計算で得られた $z, r$ 方向の流体速度 分布を利用して, Eqs. (6)，(7) に示す $z, r$ 方向の粒 子運動方程式を数值積分することにより遠心分離機部 内での粒子軌跡を求めた。なお，粒子速度について は, $z$ 方向の入口速度で無次元化を行った。

また, 部分分離効率を算出する上で十分な総粒子数 200 の粒子を塔底部入口から投入し，重液孔及び遠心 分離機部壁面へ移動した粒子数を算出しここれらが粗 粉として回収されると仮定し部分分離効率 $\Delta \eta$ を求め 


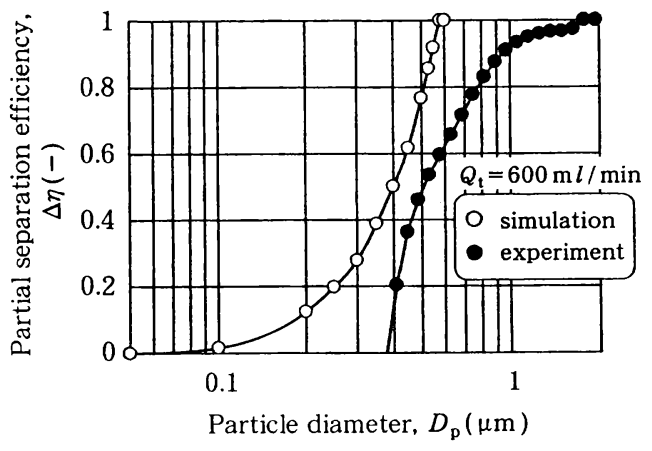

Fig. 6 Partial separation efficiency curves derived by simulation and experiment

た。

$$
\begin{aligned}
& \frac{\mathrm{d} z}{\mathrm{~d} t}=u_{\mathrm{z}}-\frac{\left(\rho_{\mathrm{p}}-\rho\right) D_{\mathrm{p}}^{2} g}{18 \mu} \frac{1}{u_{z 0}} \\
& \frac{\mathrm{d} r}{\mathrm{~d} t}=u_{\mathrm{r}}+\frac{\left(\rho_{\mathrm{p}}-\rho\right) D_{\mathrm{p}}^{2} r \omega^{2}}{18 \mu} \frac{R_{\mathrm{o}}}{u_{\mathrm{z} 0}}
\end{aligned}
$$

\section{4. 結果と考察}

\section{1 数値シミュレーション結果と考察}

\section{1.1 流量比が分離径に与える影響}

回転速度 $\omega=6000 \mathrm{rpm}$, 原料液供給流量 $Q_{\mathrm{t}}=600$ $\mathrm{m} l / \mathrm{min}$, 原料液供給流量と軽液流量の比 $\alpha=1$ の場 合の数值シミュレーションより算出した部分分離効率 曲線を Fig. 6 に示す。数値シミュレーション結果の妥 当性を検証するために，同条件における実験結果も併 記した。この図より, 数値シミュレーション結果の方 が実験結果より分離径は小さいことが分かる。これ は，数值シミュレーションでは羽根の挿入区間におけ る流体について完全剛体回転を仮定しているのに対 し，実験では羽根扱入区間の全流体に完全剛体回転を 与えることができなかったことや，3次元で取り扱う へき流体について 2 次元軸対称で解析していること等 が原因であると考えられる。しかし， $\Delta \eta=0.5$ 付近て は両者の差は狭まり, 数值シミュレーション結果に妥 当性があるものと考えられ，更に数值シミュレーショ ンにより分級性能について検討を行うことにした。

数值シミュレーションによって求めた部分分離効率 曲線上で $\Delta \eta=0.95$ を示す場合の粒子径 $D_{\mathrm{p}}$ を $D_{\mathrm{p} 95}$ と 定義し， $\alpha$ と $D_{\mathrm{p} 95}$ の関係をグラフにしたものを Fig. 7 に示す。ここで，Fig. 5 に図示したように，出口に リング状仕切板を設ける場合と設けない場合の 2 条件 の場合について数值シミュレーションを行った。

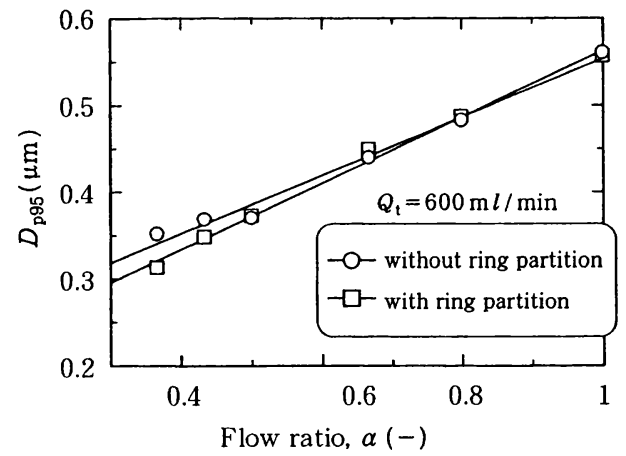

Fig. 7 Computational relationships between flow ratio and $95 \%$ cut size

仕切板を遠心分離機部出口部分に設けない場合につ いては， $\alpha$ の値が減少するにつれて，分離径 $D_{\mathrm{p} 95}$ が 小さくなっていることが分かる。これは重液流量を多 くすることで，粗粉が微粉を含む軽液側へ混入するこ とを抑制できたためだと考えられる。この傾向は，液 体サイクロンにおいて，アンダーフローの流量を増加 させることで粗粉中の微粉の混入量を低減させること ができることと同様の傾向を示している ${ }^{1.2)}$ 。

次に, Fig. 5（b）に示すように, 出口部分に外径 $2 r_{\mathrm{p}}=36.0 \mathrm{~mm}$ の仕切板を設けた場合の数值シミュ レーション結果について検討を行った。流量比 $\alpha$ の值 が同じ場合，仕切板を設けた場合と設けない場合につ いて比較すると， $\alpha<0.5$ の条件では仕切板を設ける ことで分離径 $D_{\mathrm{p} 95}$ が小さくなっていることが分か る。このことについて，詳細な検討を 4. 1. 2節で行 うことにする。

\section{1.2 遠心分離機部出口構造が粒子軌跡に与え る影響}

Fig. 7 に示した結果について，それぞれの出口構 造における数值シミュレーションにより得られた粒子 軌跡を用いて詳細な検討を行う。Fig. 8 に, $D_{\mathrm{p}}=1.0$ $\mu \mathrm{m}$ の単分散粒子の遠心分離機部内部における粒子 軌跡を示す。Fig. 8（a）は流量比 $\alpha=1.0$ の場合, Figs. 8 (b), (c) は，それぞれ $\alpha=0.37$ での遠心分離 機部出口部において外径 $2 r_{\mathrm{p}}=36.0 \mathrm{~mm}$ のリング状仕 切板を設けた場合と設けない場合の粒子軌跡を示して いる。いずれの条件においても粒子は塔底からほぼ同 じ高さの外壁面位置において捕集されており，顕著な 差違を見出すことはできなかった。

Fig. 9 は, 先程より粒子径の小さい $D_{\mathrm{p}}=0.35 \mu \mathrm{m}$ の 単分散粒子の遠心分離機部内部における粒子軌跡であ る。Fig. 9（a）より， $\alpha=1.0$ の条件では粒子の一部 


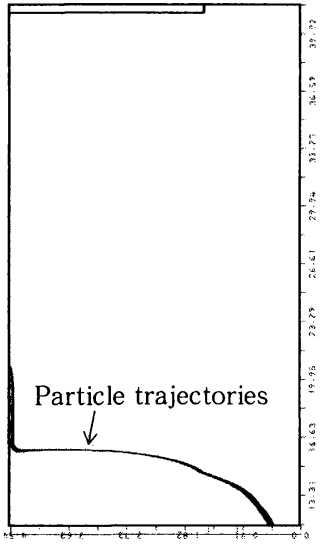

(a) $\alpha=1.0$

$D_{\mathrm{p}}=1.0 \mu \mathrm{m}$

$\Delta \eta=1.0$

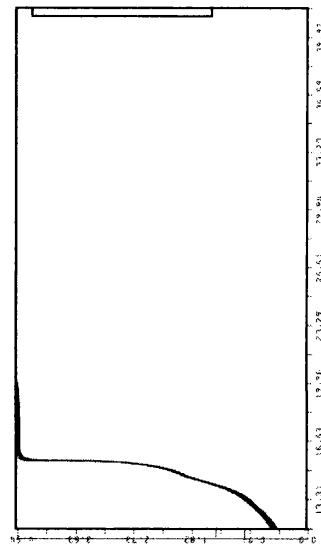

(b) $\alpha=0.37$

$D_{\mathrm{p}}=1.0 \mu \mathrm{m}$

$\Delta \eta=1.0$

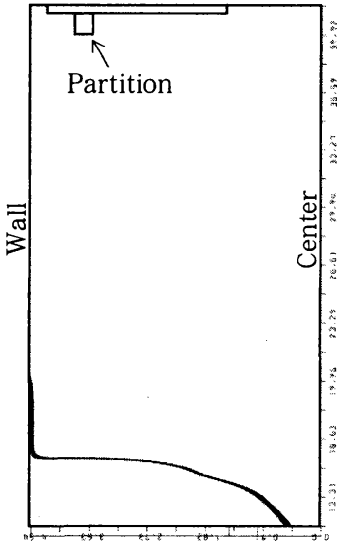

(c) $\alpha=0.37$, with ring partition $\left(2 r_{\mathrm{p}}=36.0 \mathrm{~mm}\right)$ $D_{\mathrm{p}}=1.0 \mu \mathrm{m}$

$\Delta \eta=1.0$

Fig. 8 Simulated trajectories of particles, $D_{\mathrm{p}}=1.0 \mu \mathrm{m}$, for various conditions

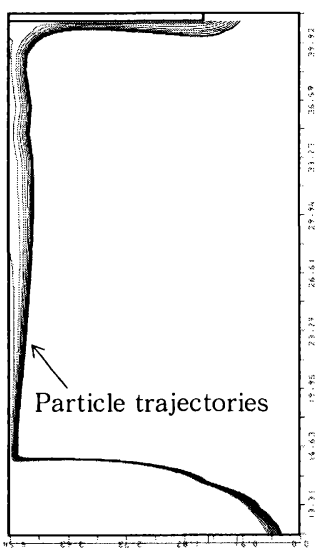

(a) $\alpha=1.0$

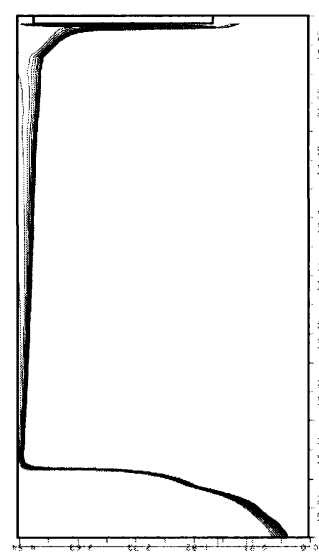

(b) $\alpha=0.37$

$D_{\mathrm{p}}=0.35 \mu \mathrm{m}$

$\Delta \eta=0.39$

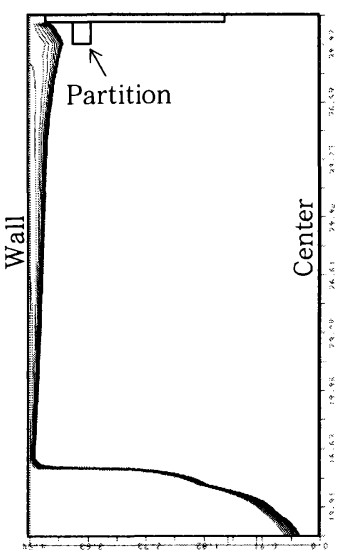

(c) $\alpha=0.37$, with ring partition $\left(2 r_{\mathrm{p}}=36.0 \mathrm{~mm}\right)$ $D_{\mathrm{p}}=0.35 \mu \mathrm{m}$ $\Delta \eta=1.0$

Fig. 9 Simulated trajectories of particles, $D_{\mathrm{p}}=0.35 \mu \mathrm{m}$, for various conditions

が壁面で捕集されているものの，そのほとんどが軽液 孔へ排出されている。Fig. 9 (b) と比較すると, 重液 孔を設けることで, 部分分離効率が 0.39 から 0.95 に 向上することが分かる。これは, 出口水平壁面に最接 近した粒子の一部が重液孔で回収されたためである。 よって $\alpha$ の值が下がるにつれて, 出口水平壁面に接近 した粒子が重液孔で回収されやすくなるので, 分離径 は小さくなると考えられる。一方, 出口に仕切板を設 けた Fig. 9 (c) の場合は, Fig. 9 (b) では軽液孔へ と向かっていた粒子が出口水平壁面手前で重液孔へ回
収され, 部分分離効率が 1.0 にまで上昇している。こ れは仕切板により粒子が出口部水平壁面へ接近及び衝 突することなく，よりスムーズに粒子が重液孔へと運 ばれているためだと考えられる。以上の考察から，粒 子が遠心分離機部塔底から流入し遠心分離機部壁面近 傍を通過し軽液孔へと排出される軌跡を描く場合に は，軽液孔へと向かう粒子をよりスムーズに重液孔へ と接近させるために，仕切板は重液孔に近い場所に設 置することが分離径を小さくすることに最も効果的で あると推察される。 


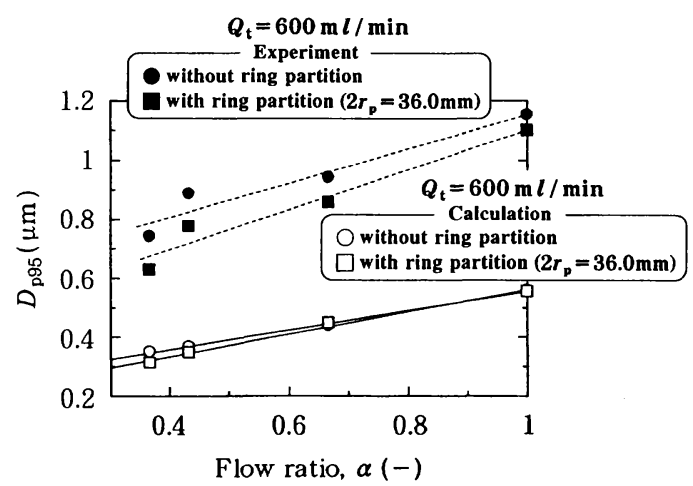

Fig. 10 Experimental and computational relationships between flow ratio and $95 \%$ cut size

\section{2 実験結果と考察}

4. 1節では, 数值シミュレーションにより流量比 $\alpha$ の值を小さくし，遠心分離機部出口部にリング状仕切 板を設けることで分離径が小さくなるという知見が得 られた。本節では，この数值シミュレーションにより 得られた知見を実験により検証した。

\section{2.1 仕切板が分離径に与える影響}

Fig. 10 は, 遠心分離機部出口に外径 $2 r_{\mathrm{p}}=36.0 \mathrm{~mm}$ のリング状仕切板を設けた場合と設けない場合につ いての, 分離径 $D_{\mathrm{p} 95}$ と流量比 $\alpha$ との関係を実験によ り検討した結果であり，4.1.1節で数值シミュレー ションにより検討した結果についても併記した。両者 は定性的に一致していることが分かる。

重液孔のない場合の実験では，実験条件によっては 遠心分離機部内部に空隙が発生するため, 遠心分離機 部壁面での捕集効率が低下する現象が見られた ${ }^{6)}$ 。し かし， $\alpha<1$ の条件では重液孔からも粗粉が回収され るため，壁面での捕集効率の低下を抑制することがで きる。よって, 分級性能を向上させるためには, 出口 に重液孔を設けることが必要であると考えられる。ま た，遠心分離機部出口部に仕切板を設けることで，数 值シミュレーション結果同様に分離径を小さくするこ とができることが分かる。実験結果は数值シミュレー ション結果を上回るが、これは4. 1. 1節でも述べた ように，実験では羽根と羽根で挟まれた全空間で数值 シミュレーションにおいて仮定した完全剛体回転を与 えることができないことや, 粒子径分布測定について 必ずしも定量的に正しい結果が得られないこと等に起 因していると考えられる。また，原料液の分散方法と しての超音波照射法だけでは本実験系において必ずし も十分ではない可能性があり，原料液を十分に分散す

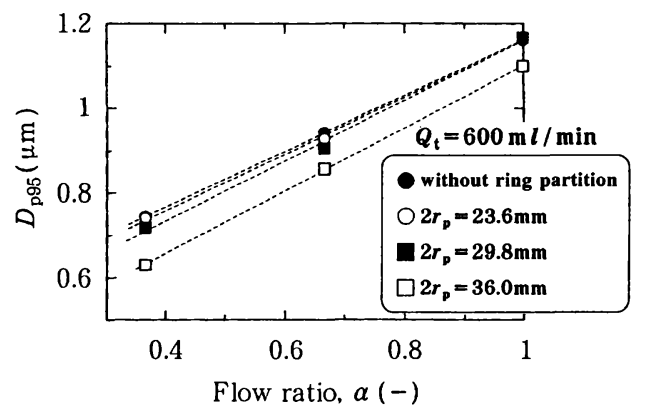

Fig. 11 Dependence of external radius of ring partition on relationships between flow ratio and $95 \%$ cut size

ることにより，より微粉側での部分分離効率に関する データが得られることになれば，実験データはより計 算結果に近づくものと予想される。

\section{2.2 仕切板径が分離径に与える影響}

4. 2. 1節では, 数值シミュレーション結果と実験 結果は定性的に一致していることを明らかにした。本 節では，4.1.2節で推察した遠心分離機部出口部に 設けるリング状仕切板の設置位置, すなわち仕切板外 径 $2 r_{\mathrm{p}}$ の変化が分級性能に及ぼす影響について実験 的に検討した。

Fig. 11は, 仕切板外径 $2 r_{\mathrm{p}}$ を変化させたときの流量 比 $\alpha$ と分離径 $D_{\mathrm{p} 95}$ の関係について実験的に検討した

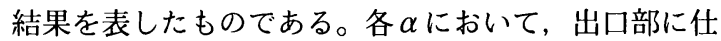
切板を設けることで分離径が小さくなっていることが 分かる。また, $2 r_{\mathrm{p}}=36.0 \mathrm{~mm}$, すなわち, 本実験で 扱った最も外径の大きい仕切板が分離径を小さくする ことに効果的であることが分かる。これは 4.1.2節 で推察したように，仕切板を重液孔に近い場所に設置 することで，粒子をより効果的に重液孔へ接近させる ことができたためだと予想され，仕切板の設置位置の 選定も分離径を小さくすることに重要な因子になると 考えられる。

以上の知見により，遠心分離機による分離径 $D_{\mathrm{p} 95}$ を小さくするには, 流量比 $\alpha$ を小さく, 出口仕切板を 重液孔近くに設置することが効果的であることが分 かった。

今後, 更に数値シミュレーションの精度を向上させ ることにより，操作条件により分級に最も効果的な仕 切板外径の予測が可能になると期待される。

\section{5. 結言}

従来の中心軸側出口に加え, 新たに外壁面側に出口 を設置し，更に二つの出口を仕切るリング状の仕切板 
を設置することにより, 改良した遠心分離機による微 粒子の分級ついて, 数值シミュレーション及び実験に より分級性能評価を行い，以下の知見を得た。

1 ) 原料液供給流量に対して軽液流量の割合を減少さ せると，分離径は小さくなる。

2 ）遠心分離機部出口にリング状仕切板を設けること で分離径を更に小さくすることが可能である。
3) 上記 1 ) 及び 2 ) の事項について, 数值シミュ レーション結果と実験結果は定性的に一致した。

4 ）分離径は肉厚一定のリング状仕切板の設置位置に 依存し，重液孔近くに仕切板を設置することが分 離径を小さくすることに最も効果的であることを 実験的に明らかにした。

\section{Nomenclature}

C : dimensionless particle concentration

$D$ : particle diffusion coefficient

$D_{\mathrm{p}}$ : particle diameter

$D_{\mathrm{p} 95}: 95 \%$ cut size of centrifugal separator

$f_{\mathrm{o}}\left(D_{\mathrm{p}}\right), f_{\mathrm{f}}\left(D_{\mathrm{p}}\right)$ : particle size distributions of feed and classified fine sides, respectively $(-/ \mu \mathrm{m})$

$g \quad:$ gravity acceleration

$\left(\mathrm{m} / \mathrm{s}^{2}\right)$

$m_{0}, m_{\mathrm{f}}$ : mass of the collected particles for feed and classified fine sides, respectively $(\mathrm{g} / \mathrm{s})$

$p \quad$ : dimensionless pressure

$(-)$

$Q_{\mathrm{t}}, Q_{\mathrm{f}} \quad$ : total inlet flow rate and fine side flow rate

$(\mathrm{m} l / \mathrm{min})$

$R_{\mathrm{o}} \quad$ : inside radius of centrifugal separator
$(-) \quad t \quad$ : dimensionless time (-)

$\left(\mathrm{m}^{2} / \mathrm{s}\right) \quad r, z$ : dimensionless radial and axial coordinates (-)

$(\mu \mathrm{m}) \quad r_{\mathrm{p}}$ : external radius of ring partition (mm)

$u_{z}, u_{\mathrm{r}}, u_{\theta}$ : dimensionless axial, radial and tangential fluid velocities (-)

$u_{z 0}$ : axial inlet velocity (m/s)

$\alpha \quad$ : ratio of fine particle's flow rate to total flow rate

$\Delta \eta$ : partial separation efficiency

$\mu \quad$ : fluid viscosity

$(\mathrm{Pa} \cdot \mathrm{s})$

$\rho, \rho_{\mathrm{p}}$ : fluid and particle density

$\left(\mathrm{kg} / \mathrm{m}^{3}\right)$

$(\mathrm{mm}) \quad \omega$ : rotational speed of centrifugal separator (rpm)

\section{References}

1) Yoshida, H., K. Fukui and Y. Isshiki : "Control of Particle Size Separation by Use of Hydrocyclone", J. Soc. Powder Technol., Japan, 34, 690-696 (1997)

2) Yoshida, H., S. Akiyama, K.Fukui and A. Kumagaya : "Particle Classification with Improved Hydro-cyclone Separator", J. Soc. Powder Technol., Japan, 38, 626-632 (2001)

3 ) Norimoto, Y., K. Fukui and H. Yoshida : "Particle Classification Performance of Hydro-cyclone with Forced-vortex Type", J. Soc. Powder Technol., Japan, 43, 666-675 (2006)

4 ) Yoshida, H., K.Fukui, T. Yamamoto, A. Hashida and N. Michitani: "Continuous Fine Particle Classification by Water-Elutriator with Applied Electro-potential",
J. Soc. Powder Technol., Japan, 43, 550-558 (2006)

5 ) Yoshida, H., U. Norimoto and K. Fukui : "Effect of blade rotation on particle classification performance of hydro-cyclones", Powder Technol., 164, 103-110 (2006)

6 ) Yamamoto, T., T. Shinya, K. Fukui and H. Yoshida : "Centrifugal Classification of Paritcles and Analysis of the Fluid Dynamics", J. Soc. Powder Technol., Japan, 44, 345-352 (2007)

7 ) Takahashi, K. : "Kiso Earozoru Kogaku”, pp. 41-42, Yokendo (1982)

8 ) Patankar, S. V.: “Numerical Heat Transfer and Fluid Flow”, pp. 113-137, Hemisphere Pub. (1980) 